\title{
Synthesis and properties of $\mathrm{N}$-substituted maleimides conjugated with 1,4-phenylene or 2,5-thienylene polymers
}

\author{
Kenjiro Onimura, Mieko Matsushima, Kazuhiro Yamabuki and Tsutomu Oishi \\ $\pi$-Conjugated polymers are particularly interesting in the field of electro-optic materials because of their desirable properties \\ such as electrical conductivity, nonlinear optics and electroluminescence. Coupling polymerizations of 2,3-dibromo- $\mathrm{N}$ - \\ substituted maleimide (DBrRMI) $(\boldsymbol{R}=$ benzyl, phenyl, cyclohexyl, $n$-hexyl and $n$-dodecyl) were carried out using palladium \\ or nickel catalysts. The number-average molecular weights of poly(RMI-alt-Ph) obtained by Suzuki-Miyaura cross-coupling \\ polymerizations of DBrRMI with benzene-1,4-boronic acid or 2,5-thiophene diboronic acid were $680-1270$ by gel permeation \\ chromatographic analyses. By contrast, Yamamoto coupling polymerizations of DBrRMI with diiodobenzene gave random \\ poly(RMI-co-Ph) results. Poly(RMI-co-Ph)s exhibited a higher thermal stability than monomer and poly(RMI-alt-Ph). \\ Copolymers showed strong photoluminescence from yellow to light blue colors in tetrahydrofuran. \\ Polymer Journal (2010) 42, 290-297; doi:10.1038/pj.2009.341; published online 27 January 2010
}

Keywords: conjugated polymer; coupling polymerization; fluorescence emission; $N$-substituted maleimide; thermal stability

\section{INTRODUCTION}

Conjugated polymers have been of interest in the field of organic optoelectronic materials for products such as polymeric light-emitting diodes. ${ }^{1-5}$ Many synthetic methods, including transition metal-catalyzed polymerization, have been reported and applied to the preparation of $\pi$-conjugated polymers. The Suzuki-Miyaura cross-coupling of boronic acid derivatives with halide compounds by palladium catalyst and Yamamoto coupling reaction of aryl halide compounds using bis $\left(1,5\right.$-cyclooctadiene)nickel $\left(\mathrm{Ni}(\mathrm{COD})_{2}\right)$ as zerovalent nickel complexes have been widely used because of relatively high yields and mild reaction temperatures. ${ }^{6-13}$

$\mathrm{N}$-Substituted maleimide derivatives (RMIs) and their polymers have been known to exhibit excellent thermal stability and electronwithdrawing properties based on a rigid five-membered ring in the backbone. In addition, cyclic imide derivatives and their polymers have been reported for $\mathrm{n}$-type organic semiconducting materials as organic transistors. ${ }^{14-19}$ Although Liu and $\mathrm{Chen}^{7}$ reported that 3,4-diphenylmaleimide copolymers exhibit orange to red photoluminescence and electroluminescence, the monomer was difficult to synthesize. ${ }^{7}$ We expect that $\pi$-conjugated poly(RMI) derivatives will show electron-deficient heterocyclic arenes such as polyphthalimide and polynaphthalimide and that their $\pi$-conjugated states can be controlled to $\mathrm{N}$-substituent on maleimide rings and comonomer units such as phenylene and thienylene. 2,3-Dibromo- $\mathrm{N}$-substituted maleimide (DBrRMI) derivatives were easily synthesized in two steps from known RMIs. ${ }^{20}$ The authors have systematically investigated the synthesis and polymerizations of various RMIs. ${ }^{21-43}$

In this paper, we describe the alternating and random copolymerizations of DBrRMIs ( $\mathrm{R}=$ benzyl, phenyl, cyclohexyl, $n$-hexyl and $n$ dodecyl) with dibromo or diboronic acid derivatives and the thermal and fluorescence emission properties of their $\pi$-conjugated polymers.

\section{EXPERIMENTAL PROCEDURE}

\section{Measurements}

${ }^{1} \mathrm{H}(270 \mathrm{MHz})$ and ${ }^{13} \mathrm{C}(68 \mathrm{MHz})$ nuclear magnetic resonance (NMR) spectra were recorded on a JEOL-EX270 spectrometer (JEOL, Tokyo, Japan) using tetramethylsilane (TMS) $\left({ }^{1} \mathrm{H}\right.$ NMR, $\left.\delta 0.00\right)$ or $\mathrm{CDCl}_{3}\left({ }^{13} \mathrm{C} \mathrm{NMR}, \delta 77.0\right)$ as internal reference peaks at room temperature. Splitting patterns were designated as $s$ (singlet), $d$ (doublet), $t$ (triplet), $q$ (quartet), $m$ (multiplet) or $b r$ (broad). Infrared (IR) spectra were recorded on an FT-IR Jasco 4100 spectrophotometer (JASCO, Tokyo, Japan). Melting points (m.p.) were determined on a YANAGIMOTO micromelting point apparatus (YANAGIMOTO, Kyoto, Japan). Gel permeation chromatographic analyses were carried out on an LC-10AS and CHROMATOPAC C-R7A plus (Shimadzu Corporation, Kyoto, Japan), using HSG-40H, HSG-20H, HSG-15H and HSG-10H columns (tetrahydrofuran (THF) as an eluent, flow rate of $1.0 \mathrm{ml} \mathrm{min}^{-1}, 50^{\circ} \mathrm{C}$ ) and equipped with an ultraviolet (UV) detector SPD-10A (Shimadzu Corporation), on the basis of standard polystyrene samples. Thermogravimetric analyses were carried 
out using an MS-Tg/DTA220 (JEOL) at a scanning rate of $10^{\circ} \mathrm{C} \mathrm{min}^{-1}$ under nitrogen $\left(100 \mathrm{ml} \mathrm{min}^{-1}\right)$. Elemental analyses were carried out on MICRO CORDER JM10 (J-SCIENCE, Kyoto, Japan).

\section{Materials}

All chemicals were used without any further purification. Tetrakis-(triphenylphosphine)palladium(0), 2-thiopheneboronic acid and 1,5-cyclooctadiene were purchased from TCI (Tokyo, Japan). N-Benzyl-2,3-dibromomaleimide and benzene-1,4-diboronic acid were purchased from Aldrich (St Louis, MO, USA). Maleic anhydride, dodecylamine, 2,5-thiophendiboronic acid and 2,5dibromothiophene were purchased from Wako Pure Chemical Industries (Osaka, Japan). $n$-Hexylamine, potassium carbonate and 2,2'-bipyridyl $\left(\alpha, \alpha^{\prime}-\right.$-) were purchased from KISHIDA REAGENTS CHEMICALS (Osaka, Japan). Hexamethyldisilazane was purchased from Azmax (Chiba, Japan) and 1,4diiodobenzene was purchased from MERCK (Gibbstown, NJ, USA). Bromine, triethylamine and anhydrous magnesium sulfate were purchased from NAKALAI TESQUE (Kyoto, Japan). Bis(1,5-cyclooctadiene) nickel (0), phenylboronic acid, 4-biphenylboronic acid, zinc chloride and sodium sulfate were purchased from Kanto Chemical (Tokyo, Japan). $n$-Hexane, ethyl acetate, THF, $N, N$ dimethylformamide, $\mathrm{CH}_{2} \mathrm{Cl}_{2}$ and $\mathrm{CHCl}_{3}$ were dried according to standard procedure and distilled under nitrogen.

Analytical thin-layer chromatography was performed on the Merck silica gel plate $60 \mathrm{~F}_{254}$. Column chromatography was performed with silica gel $60(0.063-$ $0.200 \mathrm{~mm}$, MERCK).

RMI was prepared from maleic anhydride and the corresponding primary amine by usual methods. ${ }^{44,45}$ Compounds of DBrRMI were prepared following published procedures. ${ }^{20}$

\section{Synthesis of monomer}

$\mathrm{N}$-Phenyl-2-bromomaleimide. This compound is a pale yellow solid, according to literature. ${ }^{20}$

Mp $150-152{ }^{\circ} \mathrm{C}$ (lit. $\left.150-153{ }^{\circ} \mathrm{C}\right) ;{ }^{20}{ }^{1} \mathrm{H}-\mathrm{NMR}\left(\mathrm{CDCl}_{3}\right) \delta$ (p.p.m. from TMS): $7.03(1 \mathrm{H}, \mathrm{s}, \mathrm{HC}=\mathrm{CBr}), 7.32-7.50(5 \mathrm{H}, \mathrm{m}, \mathrm{Ph})$.

$\mathrm{N}$-Phenyl-2,3-dibromomaleimide. This compound is a pale yellow solid, according to literature. ${ }^{20}$

Mp $146-148{ }^{\circ} \mathrm{C}$ (lit. $\left.160-166{ }^{\circ} \mathrm{C}\right) ;{ }^{20}{ }^{1} \mathrm{H}-\mathrm{NMR}\left(\mathrm{CDCl}_{3}\right) \delta$ (p.p.m. from TMS): 7.32-7.52 (5H, m, Ph).

$\mathrm{N}$-Cyclohexyl-2-bromomaleimide. $\mathrm{N}$-Cyclohexyl-2-bromomaleimide (BrCHMI) (5.58 g, 21.6 mmol) was obtained as a colorless solid at a $96 \%$ yield from CHMI (4.02 g, $22.5 \mathrm{mmol})$ with bromine $(2.0 \mathrm{ml}, 32.7 \mathrm{mmol})$, according to the procedure describing BrPhMI.

$R_{\mathrm{F}} 0.25$ ( $n$-hexane/ethyl acetate $\left.20 / 1 \mathrm{v} / \mathrm{v}\right) ;$ m.p. $108-110^{\circ} \mathrm{C} ;{ }^{1} \mathrm{H}-\mathrm{NMR}$ $\left(\mathrm{CDCl}_{3}\right) \delta$ (p.p.m. from TMS): 1.15-1.41 (3H, m, cyclohexyl), 1.66-1.70 (3H, m, cyclohexyl), 1.83-1.99 (2H, m, cyclohexyl), 1.98-2.11 (2H, m, cyclohexyl), 3.90-4.02 (1H, m, -CH-), $6.81(1 \mathrm{H}, \mathrm{s}, \mathrm{HC}=\mathrm{CBr})$.

$\mathrm{N}$-Cyclohexyl-2,3-dibromomaleimide. $\mathrm{N}$-Cyclohexyl-2,3-dibromomaleimide $(2.20 \mathrm{~g}, 6.53 \mathrm{mmol})$ was obtained as a colorless solid at a $94 \%$ yield from BrCHMI $(1.78 \mathrm{~g}, 6.89 \mathrm{mmol})$ with bromine $(0.70 \mathrm{ml}, 11.5 \mathrm{mmol})$, according to the procedure describing DBrPhMI.

$R_{\mathrm{F}} 0.49$ ( $n$-hexane/ethyl acetate $\left.20 / 1 \mathrm{v} / \mathrm{v}\right) ;$ m.p. $152-154{ }^{\circ} \mathrm{C} ;{ }^{1} \mathrm{H}-\mathrm{NMR}$ $\left(\mathrm{CDCl}_{3}\right) \delta$ (p.p.m. from TMS): 1.40-1.57 (3H, m, cyclohexyl), 1.88-1.93 $(3 \mathrm{H}, \mathrm{m}$, cyclohexyl), 2.04-2.09 (2H, m, cyclohexyl), 2.23-2.27 (2H, m, cyclohexyl), 4.16-4.27 (1H, m, -CH-).

Anal. Calcd. for $\mathrm{C}_{10} \mathrm{H}_{11} \mathrm{NO}_{2} \mathrm{Br}_{2}$ : C, 35.64; H, 3.29; N, 4.16. Found: C, 35.23; H, 3.03; N, 4.07.

RMI was synthesized from maleic anhydride and primary amine according to a method reported previously. ${ }^{44,45}$

$\boldsymbol{N}$ - $\boldsymbol{n}$-Hexylmaleamic acid. A solution of $n$-hexylamine $(4.37 \mathrm{~g}, 43.2 \mathrm{mmol})$ in dry ethyl acetate $(80 \mathrm{ml})$ was added dropwise to a solution of maleic anhydride $(5.08 \mathrm{~g}, 51.8 \mathrm{mmol})$ in dry ethyl acetate $(50 \mathrm{ml})$ at $0{ }^{\circ} \mathrm{C}$, and then the mixture was stirred for $20 \mathrm{~h}$ at room temperature. The solvent was removed under reduced pressure to obtain $N$ - $n$-hexylmaleamic acid ( $10.3 \mathrm{~g}, 51.7 \mathrm{mmol}$, quant.) as a colorless solid.
${ }^{1} \mathrm{H}-\mathrm{NMR}\left(\mathrm{CDCl}_{3}\right) \delta$ (p.p.m. from TMS): $0.89\left(3 \mathrm{H}, \mathrm{t}, J=6.7 \mathrm{~Hz},-\mathrm{CH}_{3}\right)$, $1.23-1.40\left(6 \mathrm{H}, \mathrm{m}\right.$, hexyl), $1.55-1.65\left(2 \mathrm{H}, \mathrm{m}\right.$, hexyl), 3.34-3.41 $\left(2 \mathrm{H}, \mathrm{m},-\mathrm{CH}_{2^{-}}\right)$, $6.32(1 \mathrm{H}, \mathrm{d}, J=12.8 \mathrm{~Hz}, \mathrm{HC}=\mathrm{CH}), 6.40(1 \mathrm{H}, \mathrm{d}, J=12.8 \mathrm{~Hz}, \mathrm{HC}=\mathrm{CH}), 7.42$ (1H, s, -NH-).

$\boldsymbol{N}$ - $\boldsymbol{n}$-Hexylmaleimide. $\quad \mathrm{N}$ - $n$-Hexylmaleamic acid $(10.3 \mathrm{~g}, 51.7 \mathrm{mmol})$ in dry benzene $(250 \mathrm{ml})$ was heated to $65^{\circ} \mathrm{C}$, and then $\mathrm{ZnCl}_{2}(7.03 \mathrm{~g}, 51.7 \mathrm{mmol})$ was added in one portion. The mixture was heated to $90^{\circ} \mathrm{C}$. $1,1,1,3,3,3$-Hexamethyldisilazane $(21.8 \mathrm{ml})$ was slowly added dropwise to the suspension with vigorous stirring. The reaction mixture was refluxed for $10 \mathrm{~h}$. The solution was cooled to room temperature, and the precipitated solid was filtered. The residue was washed with methanol, and the resulting filtrate was concentrated under reduced pressure. The residue was dissolved in ethyl acetate $(100 \mathrm{ml})$, and then the organic layer was washed with $2 \mathrm{~N} \mathrm{HCl}(50 \mathrm{ml} \times 2)$, distilled water $(50 \mathrm{ml} \times 2)$ and saturated $\mathrm{NaClaq}(50 \mathrm{ml} \times 3)$, and was dried over anhydrous magnesium sulfate. The organic solution was concentrated using an evaporator under reduced pressure. Crude $N$ - $n$-hexylmaleimide ( $n$-HMI) was purified by column chromatography on silica gel using ( $n$-hexane/ethyl acetate $8 / 1\left(\mathrm{v} / \mathrm{v} ; R_{\mathrm{F}}\right.$ $0.21)$ ) to afford $n$-HMI $(8.54 \mathrm{~g} 47.1 \mathrm{mmol}, 91 \%)$ as a pale yellow solid.

${ }^{1} \mathrm{H}-\mathrm{NMR}\left(\mathrm{CDCl}_{3}\right) \delta$ (p.p.m. from TMS): $0.86\left(3 \mathrm{H}, \mathrm{t}, J=6.6 \mathrm{~Hz},-\mathrm{CH}_{3}\right), 1.23-$ $1.29(6 \mathrm{H}, \mathrm{m}, \mathrm{hexyl}), 1.55-1.60(2 \mathrm{H}, \mathrm{m}, \mathrm{hexyl}), 3.51\left(2 \mathrm{H}, \mathrm{t}, J=7.3 \mathrm{~Hz},-\mathrm{CH}_{2^{-}}\right)$, $6.69(2 \mathrm{H}, \mathrm{s}, \mathrm{HC}=\mathrm{CH})$.

$\boldsymbol{N}$-n-Hexyl-2-bromomaleimide. $\quad \mathrm{N}$ - $n$-Hexyl-2-bromomaleimide $(4.83 \mathrm{~g}, 18.6 \mathrm{mmol})$ was obtained as a pale yellow oil at an $83 \%$ yield from $n$-HMI $(4.07 \mathrm{~g}, 22.5 \mathrm{mmol})$ with bromine $(2.0 \mathrm{ml}, 32.7 \mathrm{mmol})$, according to the procedure describing BrPhMI.

$R_{\mathrm{F}} 0.22$ ( $n$-hexane/ethyl acetate $\left.20 / 1 \mathrm{v} / \mathrm{v}\right) ;{ }^{1} \mathrm{H}-\mathrm{NMR}\left(\mathrm{CDCl}_{3}\right) \delta$ (p.p.m. from TMS): $0.88\left(3 \mathrm{H}, \mathrm{t}, J=6.6 \mathrm{~Hz},-\mathrm{CH}_{3}\right), 1.25-1.29(6 \mathrm{H}, \mathrm{m}$, hexyl $), 1.56-1.61(2 \mathrm{H}$, $\mathrm{m}$, hexyl), $3.55\left(2 \mathrm{H}, \mathrm{t}, J=7.3 \mathrm{~Hz},-\mathrm{CH}_{2}-\right), 6.86(1 \mathrm{H}, \mathrm{s}, \mathrm{HC}=\mathrm{CBr})$.

$\boldsymbol{N}$-n-Hexyl-2,3-dibromomaleimide. $\quad \mathrm{N}$ - -Hexyl-2,3-dibromomaleimide $(0.88 \mathrm{~g}, 2.60 \mathrm{mmol})$ was obtained as a pale yellow solid at an $85 \%$ yield from $\mathrm{N}$-n-hexyl-2-bromomaleimide $(0.79 \mathrm{~g}, 2.94 \mathrm{mmol})$ with bromine $(0.30 \mathrm{ml}$, $4.91 \mathrm{mmol}$ ), according to the procedure describing DBrPhMI.

$R_{\mathrm{F}} 0.36$ ( $n$-hexane/ethyl acetate $\left.20 / 1 \mathrm{v} / \mathrm{v}\right) ;$ m.p. $32-33{ }^{\circ} \mathrm{C} ;{ }^{1} \mathrm{H}$-NMR $\left(\mathrm{CDCl}_{3}\right)$ $\delta$ (p.p.m. from TMS): $0.88\left(3 \mathrm{H}, \mathrm{t}, J=6.6 \mathrm{~Hz},-\mathrm{CH}_{3}\right), 1.26-1.30(6 \mathrm{H}, \mathrm{m}$, hexyl), $1.58-1.63(2 \mathrm{H}, \mathrm{m}, \mathrm{hexyl}), 3.56\left(2 \mathrm{H}, \mathrm{t}, J=7.3 \mathrm{~Hz},-\mathrm{CH}_{2^{-}}\right)$.

Anal. Calcd. for $\mathrm{C}_{10} \mathrm{H}_{13} \mathrm{NO}_{2} \mathrm{Br}_{2}$ : C, 35.43; H, 3.86; N, 4.13. Found: C, 35.19; H, 3.77; N, 4.20.

$\boldsymbol{N}$ - $\boldsymbol{n}$-Dodecylmaleamic acid. $\quad \mathrm{N}$ - $n$-Dodecylmaleamic acid $(12.8 \mathrm{~g}, 45.0 \mathrm{mmol})$ was obtained as a colorless solid at an $87 \%$ yield from $n$-dodecylamine $(8.01 \mathrm{~g}$, $43.2 \mathrm{mmol}$ ) with maleic anhydride $(5.09 \mathrm{~g}, 51.8 \mathrm{mmol})$, according to the procedure describing $N$ - $n$-hexylmaleamic acid.

M.p. $85-86{ }^{\circ} \mathrm{C}$; ${ }^{1} \mathrm{H}-\mathrm{NMR}\left(\mathrm{CDCl}_{3}\right) \delta$ (p.p.m. from TMS): $0.88(3 \mathrm{H}, \mathrm{t}$, $\left.J=6.6 \mathrm{~Hz},-\mathrm{CH}_{3}\right), 1.26-1.31(18 \mathrm{H}, \mathrm{m}$, dodecyl $), 1.57-1.60(2 \mathrm{H}, \mathrm{m}$, dodecyl), $3.40-3.48\left(2 \mathrm{H}, \mathrm{m},-\mathrm{CH}_{2^{-}}\right), 6.26(1 \mathrm{H}, \mathrm{d}, J=12.8 \mathrm{~Hz}, \mathrm{HC}=\mathrm{CH}), 6.43(1 \mathrm{H}, \mathrm{d}$, $J=12.8 \mathrm{~Hz}, \mathrm{HC}=\mathrm{CH}), 6.70(1 \mathrm{H}, \mathrm{s},-\mathrm{NH}-)$.

$\boldsymbol{N}$-n-Dodecylmaleimide. $\quad N$ - $n$-Dodecylmaleimide $\quad(10.5 \mathrm{~g}, \quad 39.6 \mathrm{mmol})$ was obtained as a colorless solid at an $88 \%$ yield from $N$ - $n$-dodecylmaleamic acid $(12.8 \mathrm{~g}, 45.0 \mathrm{mmol})$, according to the procedure describing $n$-HMI.

$R_{\mathrm{F}} 0.50$ ( $n$-hexane/ethyl acetate $\left.5 / 1 \mathrm{v} / \mathrm{v}\right) ;$ m.p. $52-53{ }^{\circ} \mathrm{C} ;{ }^{1} \mathrm{H}-\mathrm{NMR}\left(\mathrm{CDCl}_{3}\right) \delta$ (p.p.m. from TMS): $0.88\left(3 \mathrm{H}, \mathrm{t}, J=6.7 \mathrm{~Hz},-\mathrm{CH}_{3}\right), 1.25-1.29(18 \mathrm{H}, \mathrm{m}$, dodecyl), $1.55-1.60(2 \mathrm{H}, \mathrm{m}$, dodecyl $), 3.50\left(2 \mathrm{H}, \mathrm{t}, J=7.3 \mathrm{~Hz},-\mathrm{CH}_{2^{-}}\right), 6.68(2 \mathrm{H}, \mathrm{s}$, $\mathrm{HC}=\mathrm{CH}) ;{ }^{13} \mathrm{C}-\mathrm{NMR}\left(\mathrm{CDCl}_{3}\right) \delta$ (p.p.m. from TMS): 14.07, 22.63, 26.69, $28.50,29.29,29.56,31.86,37.88,133.97,170.83$.

$\boldsymbol{N}$ - $\boldsymbol{n}$-Dodecyl-2-bromomaleimide. $\quad \mathrm{N}$ - $n$-Dodecyl-2-bromomaleimide (BrDMI) $(5.45 \mathrm{~g}, 15.8 \mathrm{mmol})$ was obtained as a pale yellow solid at $71 \%$ yield from $\mathrm{N}$ - $n$-dodecylmaleimide $(5.96 \mathrm{~g}, 22.5 \mathrm{mmol})$ with bromine $(2.0 \mathrm{ml}, 32.7 \mathrm{mmol})$, according to the procedure describing BrPhMI.

$R_{\mathrm{F}} 0.30$ (n-hexane/ethyl acetate $20 / 1$ v/v); m.p. $45-47^{\circ} \mathrm{C} ;{ }^{1} \mathrm{H}-\mathrm{NMR}\left(\mathrm{CDCl}_{3}\right) \delta$ (p.p.m. from TMS): $0.88\left(3 \mathrm{H}, \mathrm{t}, J=6.5 \mathrm{~Hz},-\mathrm{CH}_{3}\right), 1.23-1.29(18 \mathrm{H}, \mathrm{m}$, dodecyl), $1.55-1.61(2 \mathrm{H}, \mathrm{m}$, dodecyl $), 3.55\left(2 \mathrm{H}, \mathrm{t}, J=7.3 \mathrm{~Hz},-\mathrm{CH}_{2}-\right), 6.85(1 \mathrm{H}, \mathrm{s}$, $\mathrm{HC}=\mathrm{CBr}) ;{ }^{13} \mathrm{C}-\mathrm{NMR}\left(\mathrm{CDCl}_{3}\right) \ddot{a}$ (p.p.m. from TMS): 14.09, 22.64, 26.62, 28.41, $29.04,29.29,29.41,29.49,29.56,31.86,38.87,131.23,131.70,165.32,168.60$. 
$\boldsymbol{N}$ - $\boldsymbol{n}$-Dodecyl-2,3-dibromomaleimide. DBrDMI $(1.21 \mathrm{~g}, 2.86 \mathrm{mmol})$ was obtained as a pale yellow solid at a 97\% yield from BrDMI (1.02 g, $2.94 \mathrm{mmol}$ ) with bromine $(0.30 \mathrm{ml}, 4.91 \mathrm{mmol})$, according to the procedure describing DBrPhMI

$R_{\mathrm{F}} 0.44$ ( $n$-hexane/ethyl acetate $20 / 1$ v/v); m.p. $47-47^{\circ} \mathrm{C} ;{ }^{1} \mathrm{H}-\mathrm{NMR}\left(\mathrm{CDCl}_{3}\right)$ $\delta$ (p.p.m. from TMS): $0.88\left(3 \mathrm{H}, \mathrm{t}, J=6.6 \mathrm{~Hz},-\mathrm{CH}_{3}\right), 1.23-1.29(18 \mathrm{H}, \mathrm{m}$, dodecyl), $1.57-1.63\left(2 \mathrm{H}, \mathrm{m}\right.$, dodecyl), $3.60\left(2 \mathrm{H}, \mathrm{t}, J=7.3 \mathrm{~Hz},-\mathrm{CH}_{2}-\right) ;{ }^{13} \mathrm{C}-\mathrm{NMR}$ $\left(\mathrm{CDCl}_{3}\right) \delta$ (ppm from TMS): 14.10, 22.65, 26.57, 28.39, 29.02, 29.30, 29.38, 29.50, 29.56, 31.87, 39.78, 129.24, 163.91 .

Anal. Calcd. for $\mathrm{C}_{16} \mathrm{H}_{25} \mathrm{NO}_{2} \mathrm{Br}_{2}$ : C, 45.41; H, 5.95; N, 3.31. Found: C, 45.06; H, 5.67; N, 3.29.

\section{Polymerization}

All moisture-sensitive synthetic manipulations were carried out under an inert nitrogen atmosphere using Schlenk glass tubes.

Suzuki-Miyaura cross-coupling of DBrRMI with boronic acid derivatives by palladium catalyst. ${ }^{10}$ Schlenk reaction tubes were used to contain mixtures of DBrRMI $(1.00 \mathrm{mmol})$, benezene-1,4-diboronic acid or 2,5-thiophendiboronic acid $(1.00 \mathrm{mmol})$, tetrakis-(triphenylphosphine)palladium $(0)(0.010 \mathrm{mmol})$, toluene $(5 \mathrm{ml})$ and aqueous potassium carbonate $(2 \mathrm{M}, 5 \mathrm{ml})$ under nitrogen atmosphere. The mixture was vigorously stirred at $90^{\circ} \mathrm{C}$ for several polymerization times. After cooling to room temperature, the mixture was distilled with $\mathrm{CH}_{2} \mathrm{Cl}_{2}(30 \mathrm{ml})$ and then washed with $\mathrm{H}_{2} \mathrm{O}(30 \mathrm{ml})$. After drying over anhydrous sodium sulfate, the filtrate was concentrated in vacuo. The residue distilled with THF $(0.5 \mathrm{ml})$ was slowly added dropwise into a large amount of $n$ hexane $(100 \mathrm{ml})$. The precipitated polymer was separated by suction filtration, washed with $n$-hexane and dried. Purification of the polymer was performed with reprecipitation from a THF- $n$-hexane system three times and drying under vacuum at room temperature for 2 days.

Yamamoto coupling reaction of DBrRMI with aryl halide compounds using bis(1,5-cyclooctadiene) nickel $\left(\mathrm{Ni}(\mathrm{COD})_{2}\right) .^{9} \quad$ Schlenk reaction tubes were used to contain mixtures of DBrRMI $(0.40 \mathrm{mmol}), 1,5$-cyclooctadiene $(0.90 \mathrm{mmol})$, 2,2'-bipyridyl $(0.90 \mathrm{mmol})$ and 1,4-diiodebenzene or 2,5-dibromothiophene $(0.40 \mathrm{mmol})$. The mixture was supplemented with $\mathrm{Ni}(\mathrm{COD})(1.2 \mathrm{mmol})$, toluene $(3 \mathrm{ml})$ and $\mathrm{N}, \mathrm{N}$-dimethylformamide $(3 \mathrm{ml})$, and then replaced with $\mathrm{N}_{2}$. It was stirred at $80^{\circ} \mathrm{C}$ for several polymerization times, then poured into $5 \%$ acidic methanol (with $\mathrm{HCl}$ ) and the appearing precipitates were collected by filtration. Precipitates were washed with $5 \%$ acidic methanol (with $\mathrm{HCl}$ and an $\mathrm{H}_{2} \mathrm{O}$-acetone mixture) and then were dried under vacuum. The polymer distilled with THF $(0.5 \mathrm{ml})$ was slowly added dropwise into a large amount of methanol $(100 \mathrm{ml})$. Purification of the polymer was performed with reprecipitation from a THF-methanol system three times and drying under vacuum at room temperature for 2 days.

\section{RESULTS AND DISCUSSION}

\section{Synthesis and characterization}

Suzuki-Miyaura cross-coupling polymerization of DBrRMI with benzene-1,4-diboronic acid or thiophene-2,5-diboronic acid. The key five $\mathrm{N}$-substituted 2,3-dibromomaleimide monomers (DBrRMI) were prepared in two steps from $\mathrm{N}$-substituted maleimide and bromine according to the procedure described in the study by Adams et al. (Scheme 1). ${ }^{20}$ Palladium-(0)-catalyzed carbon-carbon coupling reactions with alkenyl dihalide and diboronic acid derivatives, known as the Suzuki-Miyaura cross-coupling reaction, were used to afford alternating copolymers consisting of RMI and 1,4-phenylene or 2,5thiophenylene moieties (Scheme 2). The results of the cross-coupling polymerizations of DBrRMI with benzene-1,4-diboronic acid or 2,5thiophene diboronic acid at $90{ }^{\circ} \mathrm{C}$ using $\mathrm{Pd}\left(\mathrm{Ph}_{3}\right)_{4}$ as catalyst are summarized in Table 1 . The polymerizations of maleimide monomers having benzyl, phenyl and cycolohexyl groups as an $\mathrm{N}$-substituent on the maleimide ring were of low yield (runs $1-5$ ). The polymerization of DBrPhMI with benzene-1,4-diboronic acid furnished THF-soluble

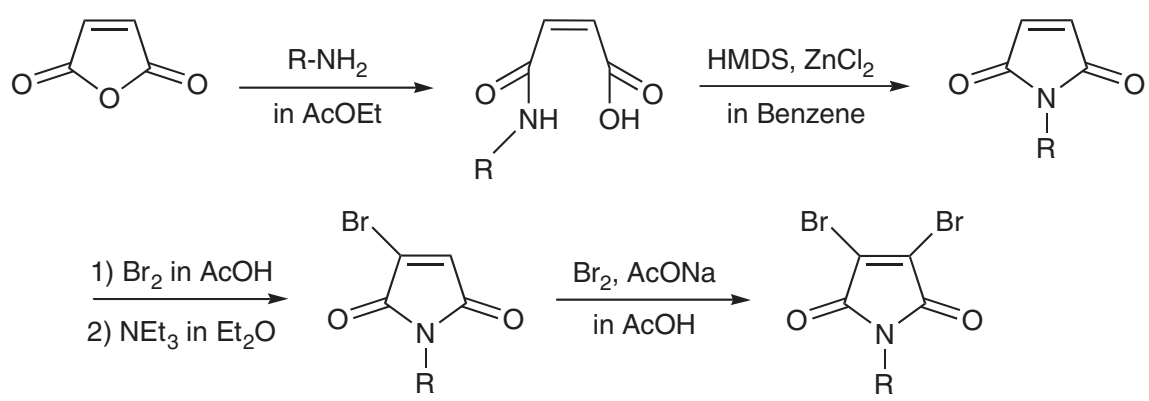

Scheme 1 Synthesis of 2,3-dibromo- $N$-substituted maleimide.

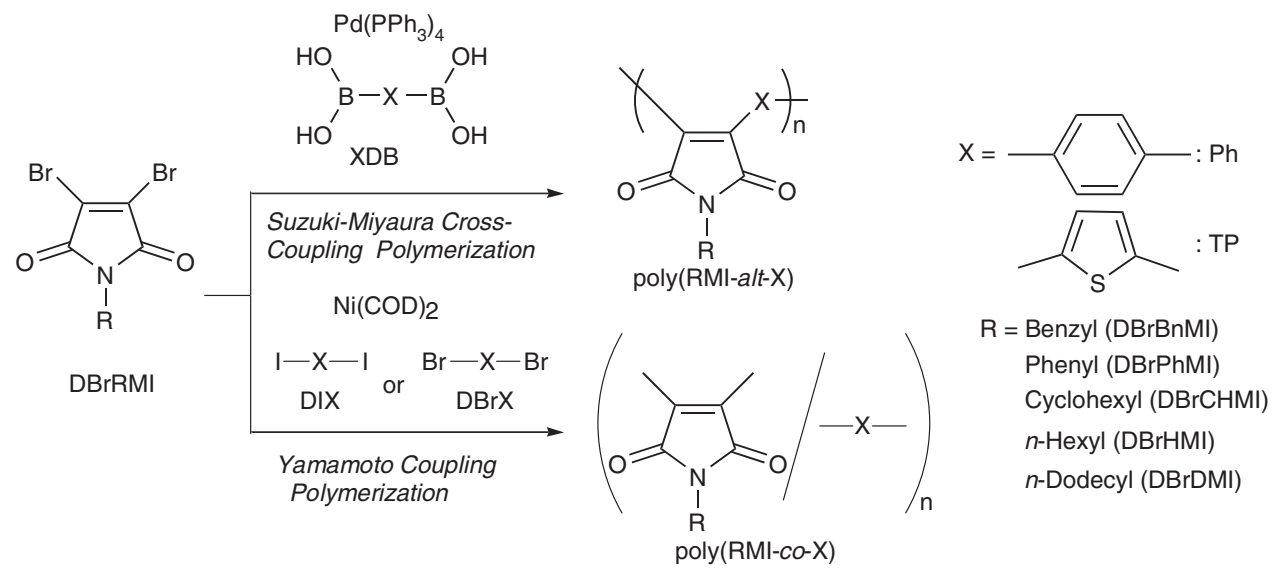

Scheme 2 Coupling polymerizations of 2,3-dibromo- $N$-substituted maleimide. 
Table 1 Suzuki-Miyaura cross-coupling polymerizations of DBrRMI with benezene-1,4-diboronic acid (PhDB) ${ }^{\mathrm{a}}$

\begin{tabular}{lccccc}
\hline Run & $\mathrm{R}$ & Time $(h)$ & Yield $^{\mathrm{b}}(\%)$ & $M_{n}{ }^{\mathrm{c}} \times 10^{-3}$ & $M_{w} / M_{n}{ }^{\mathrm{c}}$ \\
\hline 1 & & 24 & 22.7 & $0.77(1.01,0.53)$ & $1.20(1.12,1.01)$ \\
2 & $\mathrm{Bn}$ & 48 & 37.0 & 0.91 & 1.31 \\
3 & & 72 & 22.1 & $0.82(1.26,0.55)$ & $1.07(1.13,1.05)$ \\
4 & $\mathrm{Ph}$ & 48 & $11.1^{\mathrm{d} / 41.9^{\mathrm{e}}}$ & $0.68(0.86,0.45)$ & $1.20(1.11,1.02)$ \\
5 & $\mathrm{CH}$ & 48 & 17.0 & 0.95 & 1.41 \\
6 & $\mathrm{H}$ & 48 & Quant $^{\mathrm{f}}$ & 0.92 & 1.17 \\
7 & $\mathrm{D}$ & 48 & $90.0^{\mathrm{f}}$ & 1.27 & 1.34
\end{tabular}

a DBrRMI, $1.0 \mathrm{mmol}$; $\mathrm{PhDB}, 1.0 \mathrm{mmol}$; conditions: temperature, $90^{\circ} \mathrm{C}$; solvents, toluene and $\mathrm{K}_{2} \mathrm{CO}_{3}$ aq.

${ }^{b} n$-Hexane insoluble part.

${ }^{\mathrm{c} B y}$ gel permeation chromatographic with poly(styrene) standard.

dTetrahydrofuran (THF) soluble part.

eTHF insoluble part.

${ }^{\dagger} n$-Hexane soluble part.

and THF-insoluble polymers at 11.1 and $41.9 \%$ yields, respectively. Polymers obtained from $N$ - $n$-hexyl-2,3-dibromomaleimide or DBrDMI were dissolved in $n$-hexane. The number-average molecular weights $\left(M_{\mathrm{n}}\right)$ of poly (RMI-alt-Ph) obtained with benzene-1,4-boronic acid were 680-1270 (PD; 3-4 mer) by gel permeation chromatography analyses using a polystyrene standard. Gel permeation chromatography chromatographs in the range of the low-molecular-weight part showed a shoulder curve (runs 1, 3 and 4 in Table 1). The SuzukiMiyaura cross-coupling polymerizations proceeded in a biphasic solvent (toluene-aqueous $\mathrm{K}_{2} \mathrm{CO}_{3}$ ). Polymers were precipitated from the biphasic solutions because of the low solubility of substituents such as the benzyl and phenyl groups. For these reasons, the polymers obtained by the Suzuki-Miyaura cross-coupling polymerizations exhibited low yields and $M_{\mathrm{n}}$.

Figure 1 shows a representative ${ }^{1} \mathrm{H}$ NMR spectrum of poly(DMIalt $-\mathrm{Ph}$ ) in $\mathrm{CDCl}_{3}$. The signals at 0.7-1.6 and 3.2 p.p.m. are assigned to protons on the $n$-dodecyl substituent chains. The peaks that appear at 6.9-7.6 p.p.m. are due to phenylene protons. The numbers of aliphatic and aromatic protons estimated from peak integration are in good agreement with the molecular structures of the alternating copolymers.

Figures 2 and 3 show ${ }^{13} \mathrm{C}$ NMR spectra of BrDMI (a), DBrDMI (b) and poly $(\mathrm{DMI}-$ alt $-\mathrm{Ph})(\mathrm{c})$, as well as expanded spectra between 120 and 175 p.p.m. The peaks due to the $\mathrm{C}=\mathrm{C}$ double bond at $\mathrm{BrDMI}$ appear at 131.23 and 131.70 p.p.m. A single peak of DBrDMI appears at 129.24 p.p.m. Carbon peaks due to the main chain of poly(DMI-alt-Ph) are found at 134 and 132 p.p.m. The peak at 134 p.p.m. is based on the $\mathrm{C}=\mathrm{C}$ bond at the maleimide ring, formed by the carbon-carbon coupling reaction. The peak at 132 p.p.m. is due to $\mathrm{C}=\mathrm{C}-\mathrm{Br}$ at the terminal maleimide groups. The peak at 124 p.p.m. is assigned to $\mathrm{C}=\mathrm{C}-\mathrm{H}$ at the terminal polymer. According to the ${ }^{13} \mathrm{C}$ NMR spectra of $\mathrm{N}$-methyl-2-phenylmaleimide as model compounds, ${ }^{46}$ the peak at 124 p.p.m. is assigned to $\mathrm{C}=\mathrm{C}$ with a substitution of a bromine atom for a hydrogen atom. By contrast, BrDMI exhibits peaks due to $\mathrm{C}=\mathrm{O}$ at around 165.32 and 168.60 p.p.m., and DBrDMI exhibits peaks due to $\mathrm{C}=\mathrm{O}$ at around 163.91 p.p.m. The peaks at 165 and 170 p.p.m. are assigned to $\mathrm{C}=\mathrm{O}$ having bromine at the terminal polymer and $\mathrm{C}=\mathrm{O}$-bonded phenyl groups at the 2,3-positions of the maleimide, respectively.

Polymerizations of DBrRMI with thiophene-2,5-diboronic acid proceeded in a manner similar to poly(RMI-alt-Ph) at a low yield, as shown in Table 2. Poly(DMI-alt-TP)s were completely soluble in
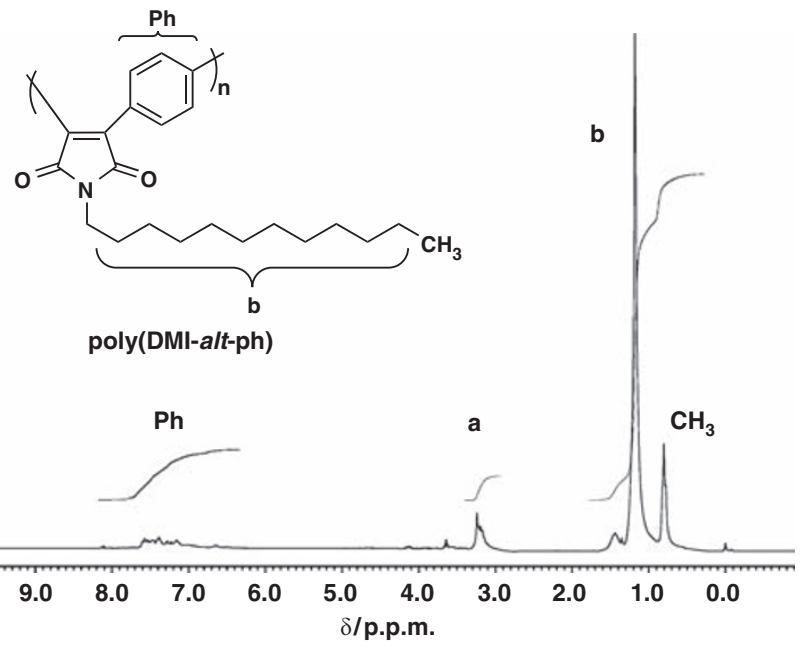

Figure $1^{1} \mathrm{H}$ NMR spectrum of poly(DMl-alt- $\mathrm{Ph}$ ) (run 7 in Table 1) $\left(R=-\mathrm{C}_{12} \mathrm{H}_{25}\right)$ in $\mathrm{CDCl}_{3}$.

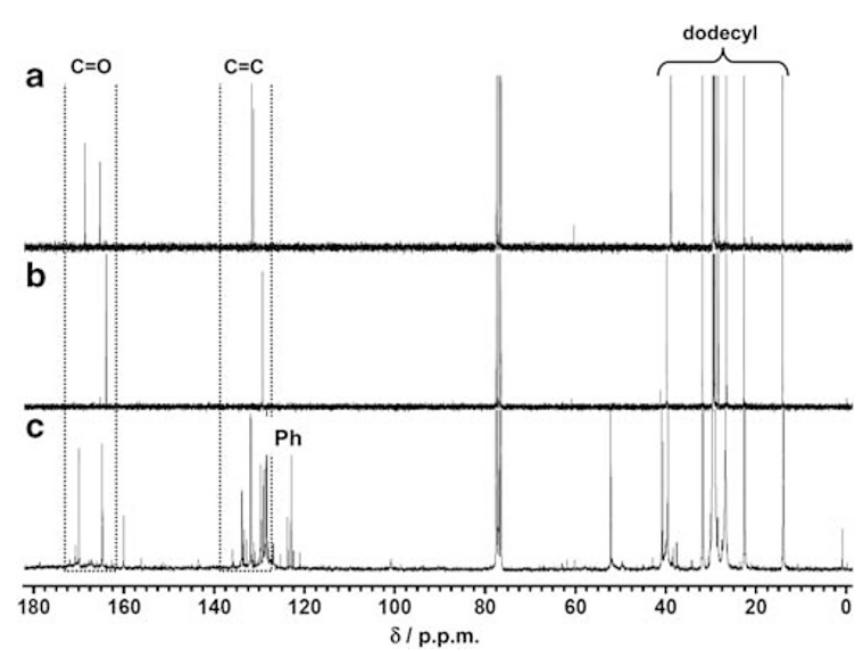

Figure $2{ }^{13} \mathrm{C}$ NMR spectra of (a) BrDMI, (b) DBrDMI and (c) poly(DMI-alt$\mathrm{Ph}$ ) (run 7 in Table 1) $\left(R=-\mathrm{C}_{12} \mathrm{H}_{25}\right)$ in $\mathrm{CDCl}_{3}$.

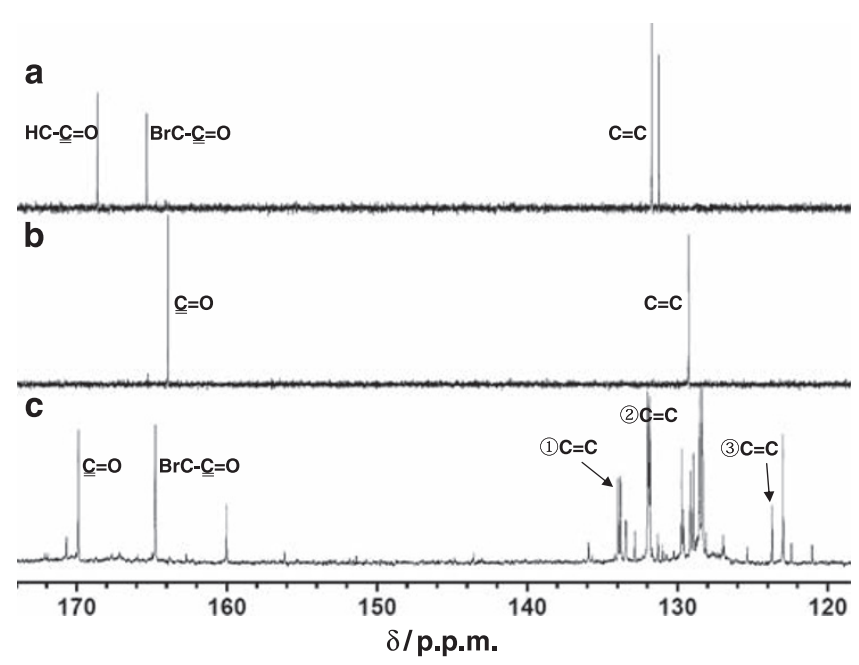

Figure 3 Expanded ${ }^{13} \mathrm{C}$ NMR spectra of (a) BrDMI, (b) DBrDMI and (c) poly(DMI-alt-Ph) (run 7 in Table 1) $\left(R=-\mathrm{C}_{12} \mathrm{H}_{25}\right)$ at $120-175$ p.p.m. in $\mathrm{CDCl}_{3}$. 
Table 2 Suzuki-Miyaura cross-coupling polymerizations of DBrRMI with 2,5-thiophendiboronic acid (TPDB) ${ }^{\mathrm{a}}$

\begin{tabular}{|c|c|c|c|c|c|}
\hline Run & $\mathrm{R}$ & Time $(h)$ & Yield $(\%)^{\mathrm{b}}$ & $M_{n}{ }^{c} \times 10^{-3}$ & $M_{w} / M_{n}{ }^{c}$ \\
\hline 1 & $\mathrm{Bn}$ & 48 & 21.4 & $0.82(1.13,0.57)$ & $1.22(1.12,1.02)$ \\
\hline 2 & $\mathrm{Ph}$ & 48 & 9.8 & $0.71(1.22,0.74)$ & $1.29(1.03,1.02)$ \\
\hline 3 & $\mathrm{CH}$ & 48 & 6.7 & $0.98(1.38,0.61)$ & $1.36(1.21,1.03)$ \\
\hline 4 & $\mathrm{H}$ & 48 & $68.5^{d}$ & $0.87(1.33,0.47)$ & $1.58(1.31,1.01)$ \\
\hline 5 & $\mathrm{D}$ & 48 & $79.2^{\mathrm{d}}$ & $1.46(2.29,0.80)$ & $1.60(1.31,1.02)$ \\
\hline
\end{tabular}

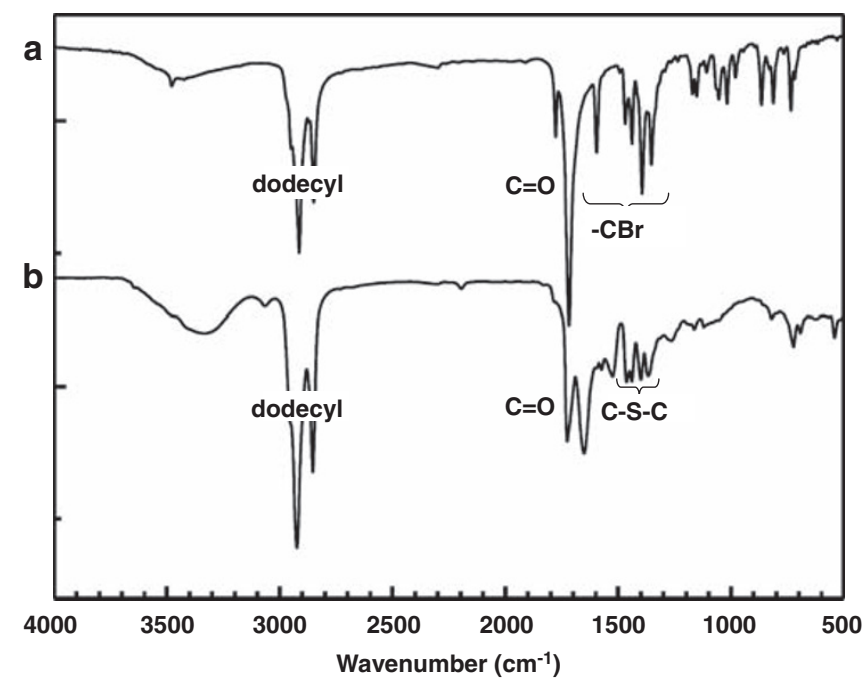

Figure $4 \mathrm{IR}$ spectra of (a) DBrDMI and (b) poly(DMI-alt-TP) (run 5 in Table 2).

Table 3 Yamamoto coupling polymerizations of DBrRMI with 1,4-diiodebenzene (DIPh) ${ }^{\mathrm{a}}$

\begin{tabular}{|c|c|c|c|c|c|c|}
\hline Run & $\mathrm{R}$ & $\begin{array}{c}\text { Time } \\
(h)\end{array}$ & $\begin{array}{l}\text { Yield } \\
(\%)^{\mathrm{b}}\end{array}$ & $M_{n}^{c} \times 10^{-3}$ & $M_{w} / M_{n}{ }^{c}$ & $\begin{array}{l}\text { RMI:Ph in } \\
\text { copolymer } \\
\text { (mol ratio) }^{\text {d }}\end{array}$ \\
\hline 1 & $\mathrm{Bn}$ & 48 & 52.3 & $1.27(1.93,0.65)$ & $1.57(1.28,1.02)$ & Not determined \\
\hline 2 & $\mathrm{Ph}$ & 48 & 86.3 & $1.34(1.68,0.64)$ & $1.45(1.29,1.01)$ & Not determined \\
\hline 3 & $\mathrm{CH}$ & 48 & 55.3 & $1.46(1.97,0.66)$ & $1.58(1.35,1.01)$ & Not determined \\
\hline 4 & $\mathrm{H}$ & 48 & 97.0 & 2.28 & 1.51 & $35: 65$ \\
\hline 5 & $\mathrm{D}$ & 48 & 75.9 & 2.89 & 1.52 & $35: 65$ \\
\hline
\end{tabular}

methanol. The polymers were isolated by reprecipitation at THF- $n$ hexane, and then they were filtered off to obtain the $n$-hexaneinsoluble part (runs 1-3). However, the polymers (of runs 4 and 5) were completely soluble in $n$-hexane, because of a longer alkyl side chain than that shown in runs $1-3 . M_{\mathrm{n}} \mathrm{s}$ were determined to be 710 1460 by gel permeation chromatography. As shown in Figure 4, the IR spectra of poly(DMI-alt-TP) show the characteristic imide group
Table 4 Yamamoto coupling polymerizations of DBrRMI with 2,5-dibromothiophene (DBrTP) ${ }^{\mathrm{a}}$

\begin{tabular}{ccccccc}
\hline Run & $\mathrm{R}$ & Time $(h)$ & Yield $^{\mathrm{b}}(\%)$ & $M_{n}{ }^{\mathrm{c}} \times 10^{-3}$ & $M_{w} / M_{n}{ }^{\mathrm{c}}$ & $\begin{array}{c}\text { RMI:TP in } \\
\text { copolymer } \\
(\text { mol ratio) }\end{array}$ \\
\hline 1 & $\mathrm{Bn}$ & 48 & 44.6 & 0.95 & 1.40 & Not determined \\
2 & $\mathrm{Ph}$ & 48 & 48.6 & 1.02 & 1.24 & Not determined \\
3 & $\mathrm{CH}$ & 48 & 57.2 & 1.32 & 1.78 & Not determined \\
4 & $\mathrm{H}$ & 48 & 44.5 & 2.33 & 2.07 & $48: 52$ \\
5 & $\mathrm{D}$ & 48 & 73.9 & 4.00 & 4.18 & $45: 55$ \\
\hline
\end{tabular}

aDBrRMI, $0.40 \mathrm{mmol}$; DBrTP, $0.40 \mathrm{mmol}$; conditions: temperature, $80^{\circ} \mathrm{C}$; solvents, toluene and $\mathrm{N}, \mathrm{N}$-dimethylformamide.

${ }^{\mathrm{MeOH}}$ insoluble part.

'By gel permeation chromatographic analysis with poly(styrene) standard.

${ }^{\mathrm{d} C}$ Calculated by ${ }^{1} \mathrm{H}$ nuclear magnetic resonance.

a
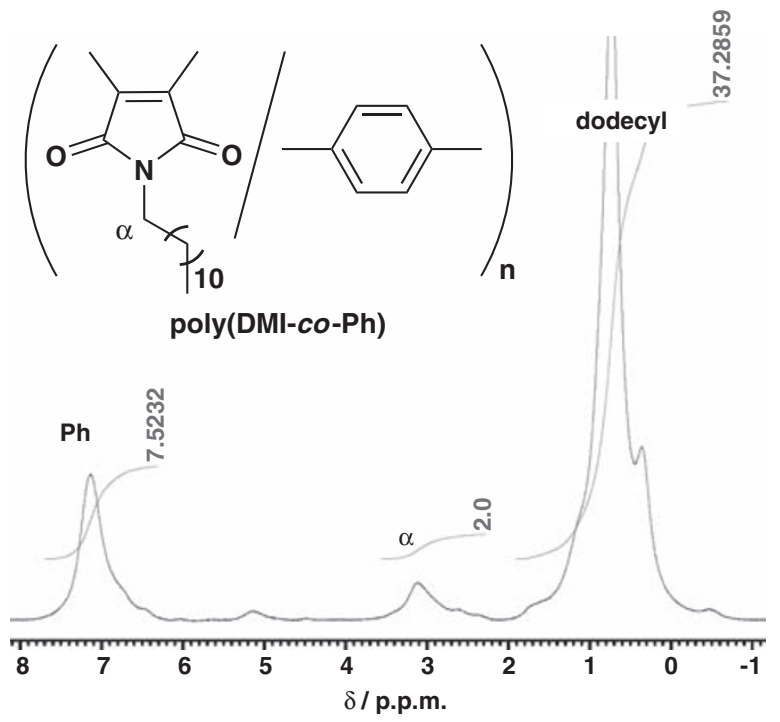

b
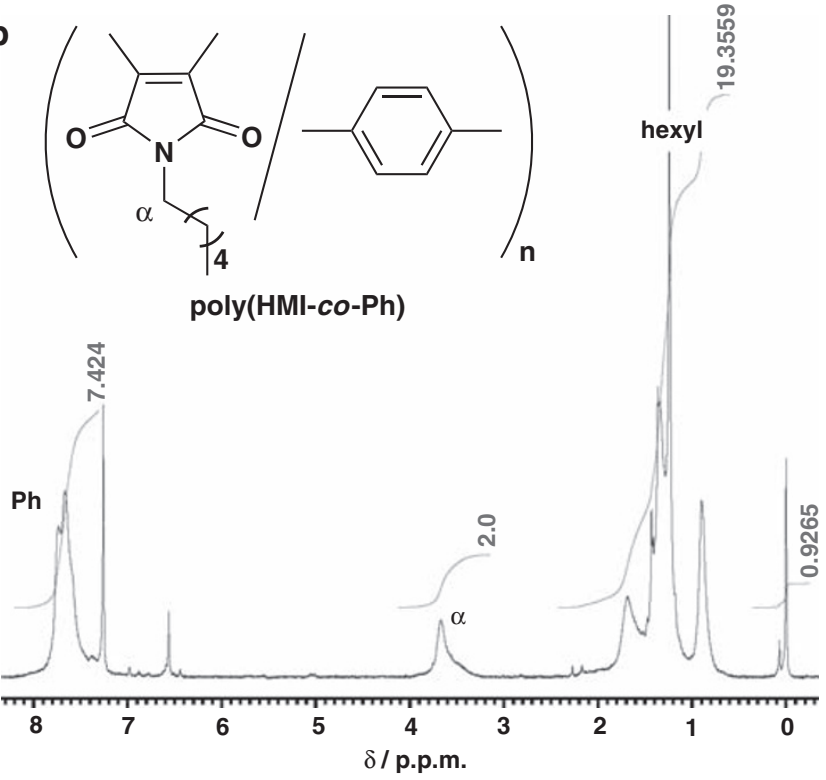

Figure $5{ }^{1} \mathrm{H}$ NMR spectra of (a) poly(DMI-co-Ph) (run 5 in Table 3) and (b) poly(HMI-co-Ph) (run 4 in Table 3) in $\mathrm{CDCl}_{3}$. 

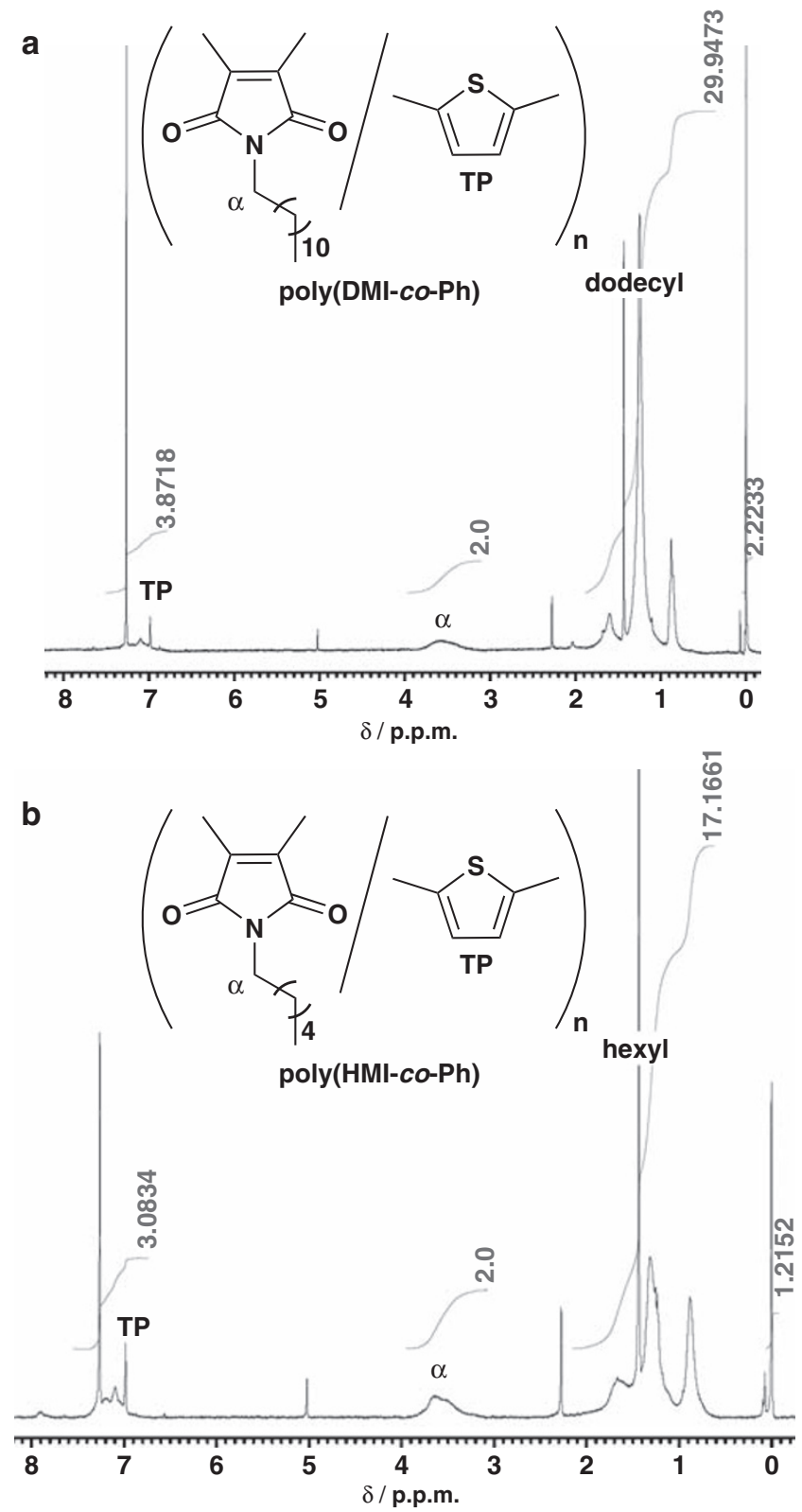

Figure $6{ }^{1} \mathrm{H}$ NMR spectra of (a) poly(DMI-co-TP) (run 5 in Table 4) and (b) poly(HMI-co-TP) (run 4 in Table 4 ) in $\mathrm{CDCl}_{3}$.

vibration band of $\mathrm{C}=\mathrm{O}$ at $1730 \mathrm{~cm}^{-1}$, which is similar to that of DBrDMI. The characteristic stretching band of $\mathrm{C}-\mathrm{Br}$ at 1350 $1600 \mathrm{~cm}^{-1}$, shown in Figure 4a, is diminished in the spectrum of poly(DMI-alt-TP). The C-S-C absorption bands in thiophene at $1360-1460 \mathrm{~cm}^{-1}$ appear in poly(DMI-alt-TP). The results derived from IR and NMR spectra indicate that polymerization was successfully carried out.

Yamamoto coupling polymerization of DBrRMI with 1,4-diiodobenzene or 2,5-dibromothiophene. We prepared random copolymers consisting of RMI and 1,4-phenylene or 2,5-thiophenylene segments by the Yamamoto coupling reaction using $\mathrm{Ni}(\mathrm{COD})_{2}$ and $2,2^{\prime}$-bipyridyl as catalyst. As shown in Tables 3 and 4, poly(RMI-co-Ph)s have $M_{\mathrm{n}}$ values of $1270-2890$ with polydispersity indices $\left(M_{\mathrm{w}} / M_{\mathrm{n}}\right)$ of $1.45-$ 1.58. The ${ }^{1} \mathrm{H}$ NMR spectra of poly(DMI-co-Ph) and poly(HMI-co-Ph)

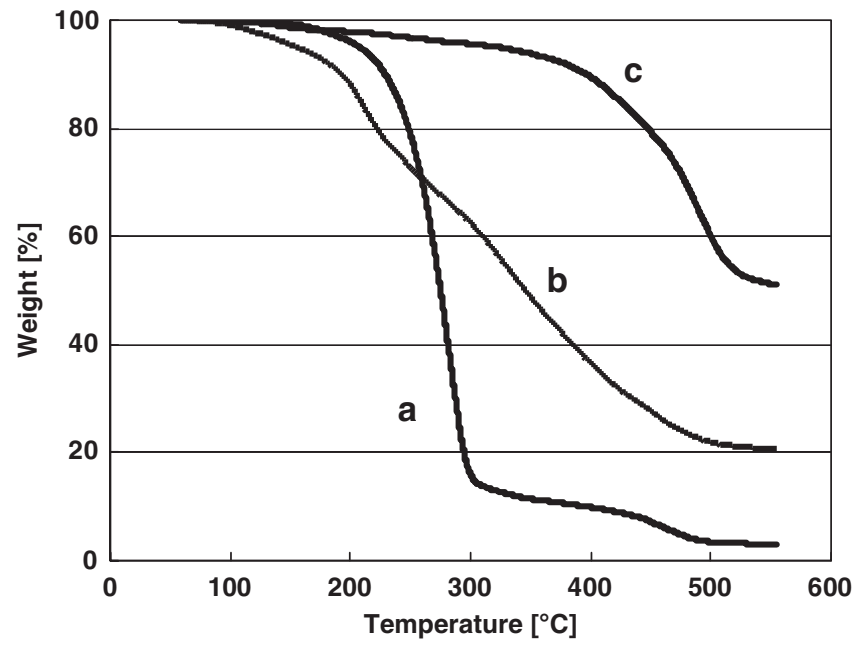

Figure 7 Thermogravimetric curves of (a) DBrDMI, (b) poly(DMl-alt-Ph) and (c) poly(DMI-co-Ph) at a heating rate of $10^{\circ} \mathrm{C} \mathrm{min}^{-1}$ in nitrogen.

Table 5 UV-visual absorption maxima and photoluminescence emission of copolymers ${ }^{\mathrm{a}}$

\begin{tabular}{|c|c|c|c|c|c|c|c|c|}
\hline \multirow[b]{2}{*}{$\mathrm{R}$} & \multicolumn{2}{|c|}{ poly $(R M I-a l t-P h)$} & \multicolumn{2}{|c|}{ poly $(R M I$-alt-TP) } & \multicolumn{2}{|c|}{$p o l y(R M I-c o-P h)$} & \multicolumn{2}{|c|}{ poly(RMI-co-TP) } \\
\hline & $\begin{array}{l}A_{\max } \\
(n m)\end{array}$ & $\begin{array}{l}\lambda_{\max } \\
(n m)\end{array}$ & $\begin{array}{l}A_{\max } \\
(n m)\end{array}$ & $\begin{array}{l}\lambda_{\max } \\
(n m)\end{array}$ & $\begin{array}{l}A_{\max } \\
(\mathrm{nm})\end{array}$ & $\begin{array}{l}\lambda_{\max } \\
(\mathrm{nm})\end{array}$ & $\begin{array}{l}A_{\max } \\
(n m)\end{array}$ & $\begin{array}{l}\lambda_{\max } \\
(\mathrm{nm})\end{array}$ \\
\hline $\mathrm{Bn}$ & $295.0,389.5$ & 542 & 293.5 & 502 & $334.5,385.5$ & 5472 & $289.5,461$. & 587.5 \\
\hline $\mathrm{Ph}$ & 295.5 & 541 & 292.5 & 501 & 315.0 & 5482 & $293.5,445$. & 593.5 \\
\hline $\mathrm{CH}$ & 298.5 & 543 & 293.0 & 517 & 313.5 & 5462 & 292.0, 467. & 591.0 \\
\hline $\mathrm{H}$ & $291.5,354.5$ & 507 & 295.5 & 483 & $337.5,407.0$ & 5462 & $291.0,455$. & 589.5 \\
\hline D & 293.5 & 503 & 295.0 & 483 & $307.0,388.5$ & 5462 & $291.0,458$. & 590.0 \\
\hline
\end{tabular}

are shown in Figure 5. Aliphatic methylene peaks $(\alpha)$ at the side chain appear between 2.39 and 3.70 p.p.m. Aromatic proton peaks at phenyl groups in the main chain, formed by the carbon-carbon coupling reaction, appear between 6.4 and 7.7 p.p.m. From the integration values of proton peaks (Figures 5 and 6 ), we could estimate that the ratios of RMI to 1,4-phenylene and 2,5-thiophenylene units are 35:65 and $45: 55$, respectively. In the same manner, the ratios of the RMI unit in copolymers were determined by ${ }^{1} \mathrm{H}$ NMR, and are shown in Tables 3 and 4 .

\section{Thermal properties}

Figure 7 indicates the thermogravimetric analyses thermograms of DBrDMI, poly(DMI-alt- $\mathrm{Ph})$ and poly(DMI-co-Ph) as indicated. The temperatures at $10 \%$ weight loss of DBrDMI, poly(DMI-alt- $\mathrm{Ph})$ and poly(DMI-co-Ph) are 229, 190 and $397^{\circ} \mathrm{C}$, respectively. The thermal stability of poly(DMI-co-Ph) was better than that of DBrDMI and poly(DMI-alt-Ph). The slight amount of weight loss in poly (DMI-alt-Ph) is probably attributed to the existence of low-molecularweight oligomers. Poly(DMI-co-Ph) shows very good thermal stability up to $\sim 400{ }^{\circ} \mathrm{C}$ under $\mathrm{N}_{2}$ atmosphere. The thermal stability of poly(DMI-co-Ph) is better than that of the poly(phenylenevinylene) derivatives (ca. $\left.300-350^{\circ} \mathrm{C}\right)^{47-50}$ and poly(biphenylenevinylene) derivatives $\left(\sim 300^{\circ} \mathrm{C}\right)^{51,52}$ reported by other groups. The results were 
ascribed not only to the maleimide ring but also to an increase of the phenylene unit.

\section{UV absorption and PL properties}

The UV-visual and fluorescence spectra of copolymers in the THF solution are summarized in Table 5. The polymers emitted strong fluorescence under UV irradiation. Poly(RMI-alt-Ph)s and poly(RMIalt-TP) displayed absorption maxima spectra at around $295 \mathrm{~nm}$ in the UV range, and these were assigned to the $\pi-\pi^{*}$ transition. However, poly(RMI-co-Ph)s and poly(RMI-co-TP) showed slightly red-shifted absorption maxima spectra. This result was attributable to the elongation of the conjugated main chain. Alternating copolymers bearing bulky substituents such as a phenyl, benzyl or cyclohexyl group are observed in the photoluminescence spectra $(542 \mathrm{~nm})$. The maximum emission spectra $\left(\lambda_{\max }\right)$ of alternating copolymers bearing linear substituents were blue-shifted about $35 \mathrm{~nm}$ relative to those of the alternating copolymers obtained with $\operatorname{DBrRMI}(\mathrm{R}=\mathrm{Ph}, \mathrm{Bn}, \mathrm{CH})$. By contrast, the random copolymers had similar emission spectra. Judging from the results of absorption and emission spectra, the photophysical properties of copolymers are influenced by $\mathrm{N}$-substituents, the kinds of comonomer units and monomer sequences.

\section{CONCLUSIONS}

We have successfully prepared alternating and random copolymers containing RMI through Suzuki-Miyaura cross coupling and Yamamoto coupling polymerizations. The polymers showed high solubilities in common organic solvents. The polymers also exhibited good thermal stability, with $10 \%$ weight loss at temperatures above $400{ }^{\circ} \mathrm{C}$. The alternating copolymers showed strong photoluminescence from yellow to light blue in THF.

1 Burroughes, J. H., Bradley, D. D. C., Brown, A. R., Marks, R. N., Mackay, K., Friend, R. H., Burn, P. L. \& Holmes, A. B. Light-emitting diodes based on conjugated polymers. Nature 347, 539-541 (1990).

2 Kraft, A., Grimsdale, A. C. \& Holmes, A. B. Electroluminescent conjugated polymersseeing polymers in a new light. Angew. Chem. Int. Ed. 37, 403-428 (1998).

3 Zhu, Y., Gibbons, K. M., Kulkarni, A. P. \& Jenekhe, S. A. Polyfluorenes containing dibenzo[a,c]phenazine segments: synthesis and efficient blue electroluminescence from intramolecular charge transfer states. Macromolecules 40, 804-813 (2007).

4 Wu, W. C., Liu, C. L. \& Chen, W. C. Synthesis and characterization of new fluoreneacceptor alternating and random copolymers for light-emitting applications. Polymer 47, 527-538 (2006)

5 Lee, W. Y., Cheng, K. F., Wang, T. F., Hueh, C. C., Hen, W. C., Tuan, C. S. \& Lin, J. L. Effects of acceptors on the electronic and optoelectronic properties of fluorene-based donor-acceptor-donor copolymers. Macromol. Chem. Phys. 208, 1919-1927 (2007).

6 Yeh, H.- C., Wu, W.- C. \& Chen, C.- T. The colourful fluorescence from readilysynthesised 3,4-diaryl-substituted maleimide fluorophores. Chem. Commun. 39, 404-405 (2003)

7 Liu, T.- Z. \& Chen, Y. Synthesis, optical and electrochemical properties of luminescent polymers containing 1,2-diphenylmaleimide and thiophene segments. Polymer 46, 10383-10391 (2005).

8 Chan, L.- H., Lee, Y.- D. \& Chen, C.- T. Synthesis and characterization of 3,4-diphenylmaleimide copolymers that exhibit orange to red photoluminescence and electroluminescence. Macromolecules 39, 3262-3269 (2006).

9 Yang, N. C. \& Suh, D. H. Introduction of diphenylmaleimide moieties into the main chain of fully $\pi$-conjugated poly(arylene ethynylene)s as 'Kink' structures. Macromol. Rapid. Commun. 22, 335-338 (2001).

10 Hwang, J. I., Yang, N. C., Choi, T. \& Suh, D. H. The synthesis and redox-induced off-on $\mathrm{PL}$ properties of poly(3,4-bisphenyl- $N$-methylferrocene-pyrrole-2,5-dione). Polymer 43, 5257-5261 (2002).

11 Yang, N. C. \& Suh, D. H. A class of cis-polyarylenevinylene: preparation and optical properties of the oligomeric polyarylenevinylene derivative having an 1,2-diphenylmaleimide moiety. Polymer 42, 7987-7992 (2001).

12 Yang, N. C., Choi, H. W., Lee, J. K., Hwang, J. I. \& Suh, D. H. A novel diphenylmaleimide dye for fluorescence photopatterned images. Chem. Lett. 31, 824-825 (2002).

13 Chan, L.- H., Lee, Y.- D. \& Chen, C.- T. 3,4-Diphenylmaleimide-thiophene-fluorene copolymers for polymeric orange-red light-emitting diodes. Org. Electron. 7, 55-59 (2006)
14 Katz, H. E., Lovinger, A. J., Johnson, J., Llock, C., Siegrist, T., Li, W., Lin, Y.- Y. \& Dodabalapur, A. A soluble and air-stable organic semiconductor with high electron mobility. Nature 404, 478-481 (2000).

15 Malenfant, P. R. L., Dimitrakopoulos, G. J. D., Kosbar, L. L., Graham, T. O., Curioni, A. \& Andreoni, W. $\mathrm{N}$-type organic thin-film transistor with high field-effect mobility based on a $N, N^{\prime}$-dialkyl-3,4,9,10-perylene tetracarboxylic diimide derivative. Appl. Phys. Lett. 80, 2517-2519 (2002).

16 Unni, K. N. N., Pandey, A. K., Alem, S. \& Nunzi, J.- M. Ambipolar organic field-effect transistor fabricated by co-evaporation of pentacene and $N, N$-ditridecylperylene-3,4,9,10-tetracarboxylic diimide. Chem. Phys. Lett. 421, 554-557 (2005).

17 Chen, H. Z., Shi, M.- M., Aernouts, T., Wang, M., Borghs, G. \& Heremans, P. A novel organic n-type material: fluorinated perylene diimide. Sol. Energy Mater. Sol. Cells 87, 521-527 (2005).

18 Letizia, J. A., Salata, M. R., Tribout, C. M., Facchetti, A., Ratner, M. A. \& Marks, T. J. $\mathrm{n}$-Channel polymers by design: optimizing the interplay of solubilizing substituents, crystal packing, and field-effect transistor characteristics in polymeric bithiopheneimide semiconductors. J. Am. Chem. Soc. 130, 9679-9694 (2008).

19 Guo, X. \& Watson, M. D. Conjugated polymers from naphthalene bisimide. Org. Lett. $10,5333-5336$ (2008).

20 Choi, D.- S., Huang, S., Huang, M., Barnard, T. S., Adams, R. D., Seminario, J. M. \& Tour, J. M. Revised structures of $\mathrm{N}$-substituted dibrominated pyrrole derivatives and their polymeric products. Termaleimide models with low optical band gaps. J. Org. Chem. 63, 2646-2655 (1998).

21 Oishi, T., Yamasaki, H. \& Fujimoto, M. Asymmetric polymerization of $\mathrm{N}$-substituted maleimides. Polym. J. 23, 795-804 (1991).

22 Onimura, K., Tsutsumi, H. \& Oishi, T. Asymmetric polymerization of $\mathrm{N}$-substituted maleimides with organolithium—bisoxazolines complex. Polym. Bull. 39, 437-444 (1997).

23 Onimura, K., Tsutsumi, H. \& Oishi, T. Asymmetric anionic polymerization of $\mathrm{N}$-substituted maleimides with $\mathrm{Et}_{2} \mathrm{Zn}$ and chiral bisoxazolines. Chem. Lett. 27, 791-792 (1998).

24 Onimura, K., Tsutsumi, H. \& Oishi, T. Asymmetric anionic polymerization of $\mathrm{N}$ substituted maleimides with $n$-butyllithiummethylene-bridged 2,2-bis(oxazoline) complexes. Macromolecules 31, 5971-5976 (1998).

25 Oishi, T., Onimura, K., Tanaka, K., Horimoto, W. \& Tsutsumi, H. Asymmetric polymerization of $\mathrm{N}$-substituted maleimides with chiral oxazolidine - organolithium. J. Polym. Sci. Part A, Polym. Chem. 37, 473-482 (1999).

26 Oishi, T., Onimura, K., Isobe, Y. \& Tsutsumi, H. First determination of absolute stereochemistry of $\mathrm{N}$-naphthylmaleimide polymer. Chem. Lett. 28, 673-674 (1999).

27 Oishi, T., Onimura, K., Isobe, Y., Yanagihara, H. \& Tsutsumi, H. Asymmetric anionic polymerization of maleimides bearing bulky substituents. J. Polym. Sci. Part A. Polym. Chem. 38, 310-320 (2000).

28 Zhou, H., Onimura, K., Tsutsumi, H. \& Oishi, T. Asymmetric anionic polymerization of $(R)-(+)-\mathrm{N}-\alpha$-methylbenzylmaleimide with chiral ligand/organometal complex. Polym. J. 32, 552-559 (2000).

29 Oishi, T., Onimura, K., Sumida, W., Zhou, H. \& Tsutsumi, H. Asymmetric group transfer polymerization of $\mathrm{N}$-cyclohexylmaleimide with lewis acid and chiral ligand complexes. Polym. J. 32, 722-728 (2000).

30 Oishi, T., Lee, Y.- K., Nakagawa, A., Onimura, K. \& Tsutsumi, H. Synthesis and polymerization of poly( $\mathrm{N}$-substituted maleimide) macromonomers. Polym. J. 33, 81-88 (2001).

31 Zhou, H., Onimura, K., Tsutsumi, H. \& Oishi, T. Synthesis and chiroptical properties of (S)-(-)- $N$ - $\alpha$-methylbenzylmaleimide polymers containing crystallinity. Polym. J. 33, 227-235 (2001).

32 Isobe, Y., Onimura, K., Tsutsumi, H. \& Oishi, T. Asymmetric anionic polymerization of $\mathrm{N}$-1-naphthylmaleimide with chiral ligand-organometal complexes in toluene. J. Polym. Sci. Part A, Polym. Chem. 39, 3556-3565 (2001).

33 Isobe, Y., Onimura, K., Tsutsumi, H. \& Oishi, T. Asymmetric polymerization of $\mathrm{N}$-1-naphthylmaleimide with chiral anionic initiator: preparation of highly optically active poly( $\mathrm{N}$-1-naphthylmaleimide). Macromolecules 34, 7617-7623 (2001).

34 Onimura, K., Zhang, Y., Yagyu, M. \& Oishi, T. Asymmetric anionic polymerization of optically active $N$-1-cyclohexylethylmaleimide. J. Polym. Sci. Part A: Polym. Chem. 42, 4682-4692 (2004).

35 Zhang, Y., Onimura, K., Tsutsumi, H. \& Oishi, T. Asymmetric anionic polymerization of (S)-(-)-N-maleoyl-L-valine methyl ester. Polym. J. 36, 878-887 (2004).

36 Lee, Y.- K., Kitamura, S., Onimura, K., Tsutsumi, H. \& Oishi, T. Asymmetric polymerization of $N$-1-naphthylmaleimide with $(R, R)-N, N$-bis(3,5-di-tert-butylsalicylidene)1,2- cyclohexanediaminatocobalt (II). J. Polym. Sci. Part A: Polym. Chem. 42, 6157-6162 (2004).

37 Gao, H., Isobe, Y., Onimura, K. \& Oishi, T. Synthesis and polymerization of novel (S)- $N$-maleoyl-L-leucine propargyl ester. Polym. J. 38, 1288-1291 (2006).

38 Isobe, Y., Onimura, K., Tsutsumi, H. \& Oishi, T. Asymmetric polymerization of $\mathrm{N}-1$ anthrylmaleimide with diethylzinc - chiral ligand complexes and optical resolution using the Polymer. Polym. J. 34, 18-24 (2002)

39 Oishi, T ., Isobe, Y., Onimura, K. \& Tsutsumi, H. Asymmetric polymerization of $\mathrm{N}$-ortho- or para-substituted phenylmaleimide using chiral anionic initiators. Polym. J. 35, 245-254 (2003).

40 Oishi, T., Zhang, Y., Fukushima, T. \& Onimura, K. Asymmetric anionic polymerizations of $(R)-N$-Maleoyl-D-phenylglycine alkyl esters and optical resolution using their Polymers. Polym. J. 37, 453-463 (2005). 
41 Gao, H., Isobe, Y., Onimura, K. \& Oishi, T. Synthesis and asymmetric polymerization of (S)-N-maleoyl-L-leucine propargyl ester. J. Polym. Sci. Part A: Polym. Chem. 45, 3722-3738 (2007).

42 Gao, H., Isobe, Y., Onimura, K. \& Oishi, T. Asymmetric polymerization of ( $S$ )- N-maleoylL-leucine allyl ester and chiral recognition ability of its polymer as chiral stationary phase for HPLC. Polym. J. 39, 764-776 (2007).

43 Oishi, T., Gao, H., Nakamura, T., Isobe, Y. \& Onimura, K. Asymmetric polymerizations of $\mathrm{N}$-substituted maleimides bearing I-leucine ester derivatives and chiral recognition abilities of their polymers. Polym. J. 39, 1047-1059 (2007).

44 Reddy, P. Y., Kondo, S., Toru, T. \& Ueno, Y. Lewis acid and hexamethyldisilazanepromoted efficient synthesis of $\mathrm{N}$-Alkyl- and $\mathrm{N}$-arylimide derivatives. J. Org. Chem. 62, 2652-2654 (1997).

45 Reddy, P. Y., Kondo, S., Fujita, S. \& Toru, T. Efficient synthesis of fluorophore-linked maleimide derivatives. Synthesis 1998, 999-1002 (1998).

46 Manley-King, C. I., Terre'Blanche, G., Castagnoli, N. Jr., Bergh, J. J. \& Petzer, J. P. Inhibition of monoamine oxidase B by $\mathrm{N}$-methyl-2-phenylmaleimides. Bioorg. Med. Chem. 17, 3104-3110 (2009).

47 Ahn, T., Jang, M. S., Shim, H.- K., Hwang, D.- H. \& Zyung, T. Blue electroluminescent polymers: control of conjugation length by kink linkages and substituents in the poly(p-phenylenevinylene)-related copolymers. Macromolecules 32, 3279-3285 (1999).

48 Lutsen, L., Adriaensens, P., Becker, H., Van Breemen, A. J., Vanderzande, D. \& Gelan, J. New synthesis of a soluble high molecular weight poly(arylene vinylene): poly[2-methoxy-5-(3,7-dimethyloctyloxy)-p-phenylene vinylene]. polymerization and device properties. Macromolecules 32, 6517-6525 (1999).

49 Fan, Q.- L., Zhang, G.- W., Lu, X.- M., Chen, Y., Huang, Y.- Q., Zhou, Y., Chan, H. S. O., Lai, Y.- H., Xu, G.- Q. \& Huang, W. Cationic phenyl-substituted poly(p-phenylenevinylene) related copolymers with efficient photoluminescence and synthetically tunable emissive colors. Polymer 46, 11165-11173 (2005).

50 Chang, H. -T., Lee, H. -T., Chang, E. -C. \& Yeh, M. -Y. Effects of a tert-butylphenylene substituent on the structure and optical, fluorescent and thermal properties of the poly(p-phenylenevinylene) derivatives. Polym. Eng. Sci. 47, 1380-1387 (2007).

51 Yamamoto, T., Xu, Y., Inoue, T. \& Yamaguchi, I. Preparation of poly(biphenylene vinylene) type polymers by $\mathrm{Ni}$-promoted polycondensation and their basic optical properties. J. Polym. Sci. Part A: Polym. Chem. 38, 1493-1504 (2000).

52 Gruber, J. \& Li, R. W. C. Electrochemical synthesis of poly(4,4'-biphenylenevinylene)s (PBPVs). J. Mater. Chem. 9, 1461-1464 (1999). 